A idade,

\section{a massa \\ e a expansão \\ do universo \\ universo}

$$
\begin{gathered}
\therefore \\
\therefore
\end{gathered} \therefore
$$

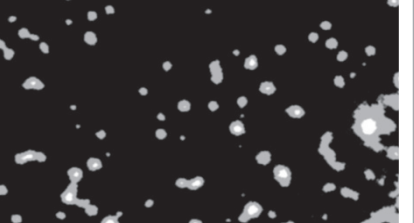

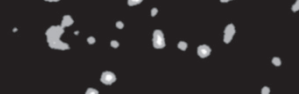


idade do universo é discutida a partir dos diferentes indicadores: idade de aglomerados globulares, idade a partir de abundância de urânio em estrelas velhas, seqüiência de resfriamento de anãs brancas, constante de Hubble, e medidas de flutuação da radiação de fundo.

A expansão do universo e as recentes evidências de sua expansão acelerada a partir de observações de supernovas de tipo Ia serão discutidas, em conexão com a massa do universo. A massa em bárions é dada por medidas de elementos $\mathrm{H}, \mathrm{He}$, Li produzidos no big-bang; a massa escura determinada a partir de dinâmica de aglomerados de galáxias; a energia escura evidenciada pela expansão acelerada do universo e pelas medidas de radiação de fundo.

\section{INDICADORES DA IDADE DO UNIVERSO}

\section{Idade dos aglomerados globulares}

Os aglomerados globulares são os primeiros objetos a se formar em galáxias no início de seu processo de formação. São constituídos de 10.000 a 100.000 estrelas, formadas ao mesmo tempo, com semelhante composição química, e se encontrando todas à mesma distância de nós.

As estrelas de um aglomerado se distribuem em diferentes estágios evolutivos: estrelas anãs, subgigantes, gigantes, de ramo horizontal e ramo assintótico das gigantes. 
Ao passar do estágio de anã para subgigante, a estrela passa pelo ponto de turn-off, ou seja, até ali sua temperatura vinha aumentando, e a partir desse ponto volta a esfriar.

A evolução das estrelas ao longo dessas fases é bem conhecida e pode ser calculada em computadores. A idade dos aglomerados globulares é obtida comparando-se os cálculos com as observações.

A principal incerteza se deve à imprecisão das distâncias dos aglomerados. A idade obtida é da ordem de 14 bilhões de anos, como ilustrado na Figura 1. Essa figura mostra o diagrama cor-magnitude do aglomerado globular M92 do halo da galáxia. Vêem-se nesse diagrama os pontos observados e as linhas sólidas correspondendo a

\section{Figura 1}

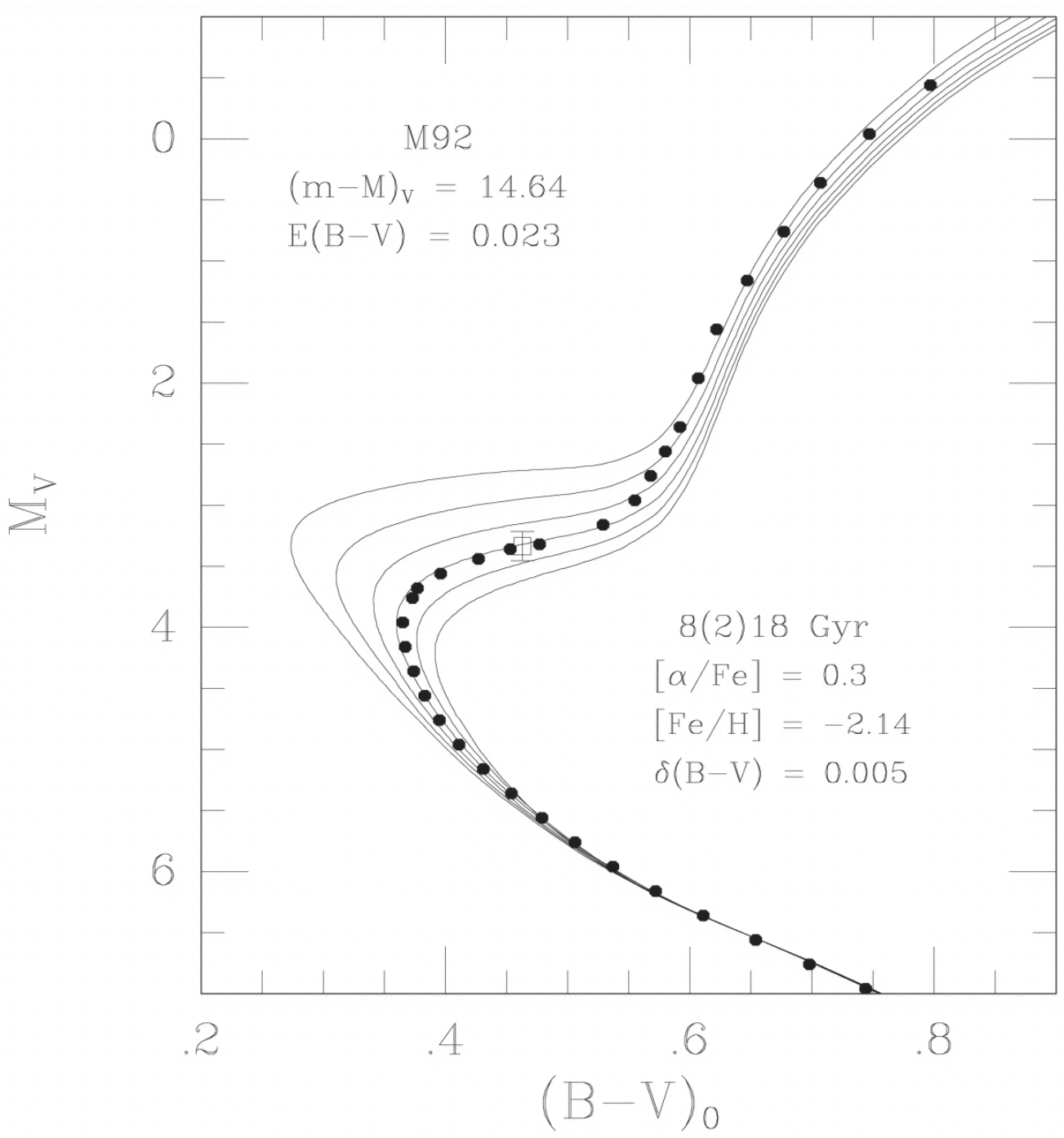

Diagrama cor-magnitude do aglomerado globular M92 do halo da galáxia. Os pontos são as observações, e as linhas sólidas correspondem a cálculos para diferentes idades. O ponto de turn-off define a idade (tirada de Grundahl et al. 2000, Astronomical Journal 120, 1884). 
cálculos para diferentes idades. O ponto de turn-offé sensível à idade, sendo portanto usado para determiná-la.

\section{Idade das estrelas mais velhas, medida com decaimento do urânio}

As estrelas mais velhas, encontradas no halo da galáxia, são muito pobres em metais. A idade das estrelas mais velhas da galáxia indica a época em que começou a formação de estrelas, e isso dá uma idade mínima para o universo. A datação radioativa baseia-se em comparar a razão de abundâncias de uma espécie radioativa com uma espécie estável, tendo sido ambas formadas em um mesmo processo nucleossintético. No presente caso, trata-se do processo "r", que designa "rápida captura de nêutrons", ocorrendo em explosões de supernovas.

Em 2001 foi possível pela primeira vez medir a abundância do elemento radioativo urânio $\left({ }^{238} \mathrm{U}\right)$ numa estrela velha da galáxia. Esse cosmocronômetro é o método mais direto de determinação de idade da galáxia, a qual resultou ser de $14.0 \pm 2.4$ bilhões de anos.

\section{Seqüência de resfriamento de}

\section{anãs brancas}

Após a fase de ramo assintótico das gigantes, as estrelas passam a perder camadas exteriores, e expor suas camadas mais internas, e portanto aparecem mais quentes no diagrama cor-magnitude. A partir de um certo ponto, não perdem mais camadas e passam, ao contrário, a esfriar lentamente: é a fase de anã branca, em que a pressão dos elétrons circulando numa matéria degenerada é a principal fonte de energia que as mantém contra um colapso gravitacional

No diagrama cor-magnitude, isso aparece como a seqüência de anãs brancas, que aparecerão cada vez mais fracas, por estarem esfriando e perdendo energia ao longo do tempo. Assim sendo, se pudermos detectar o final da seqüência de resfriamento das anãs brancas, podemos derivar a idade de um aglomerado globular.

A determinação do fim da seqüência de anãs brancas do aglomerado globular M4 foi obtida com 123 órbitas do telescópio espacial Hubble, atingindo a magnitude $\mathrm{V}=30$. Esse resultado foi anunciado em 2003, dando uma idade de $12.7 \pm 0.7$ bilhões de anos, o que nos dá a idade da galáxia.

\section{A constante de Hubble}

A lei de Hubble estabelece que a velocidade das galáxias cresce linearmente com a distância: $\mathrm{v}=\mathrm{H}_{0} \mathrm{r}$, onde $\mathrm{H}_{0}$ é o parâmetro ou constante de Hubble.

O resultado mais confiável atualmente é o do projeto realizado com o telescópio espacial Hubble, que dá $\mathrm{H}_{0}=72 \pm 7 \mathrm{~km} / \mathrm{s} / \mathrm{Mpc}$, valor anunciado em $2001 . \mathrm{H}_{0}$ tem unidades de tempo, e $1 / \mathrm{H}_{0}={ }_{\mathrm{H}}$ é chamado o "tempo de Hubble", da ordem de 13 bilhões de anos . Porém isso não dá diretamente a idade do universo, mas representa apenas um limite superior à idade que chamaremos de $t_{\text {universo }}$. Isso porque a determinação da idade depende da dinâmica do universo, de quanta matéria ele contém, e da sua geometria no espaço-tempo.

No modelo cosmológico de Friedman (que é o modelo de universo mais básico e mais simples), e adotando-se uma constante de curvatura do espaço-tempo $\mathrm{k}=0$, e o parâmetro de densidade do universo $\Omega=1$, ou seja, universo com densidade de massa exatamente igual à densidade crítica acima da qual o universo se recontrairia, obtémse $\mathrm{t}_{\text {universo }}=2 / 3 \mathrm{H}_{0}$.

Porém, com a recente confirmação da existência da "energia escura", o que equivale a considerar-se a constante cosmológica como originalmente definida por Einstein nas equações que descrevem o universo, obtém-se $\mathrm{t}_{\text {universo }}=2 / 3 \mathrm{H}_{\mathrm{o}} \Omega_{0, m}^{-0.3}$, onde $\Omega_{0, m}$ é o parâmetro de densidade de 
matéria no universo, de valor 0.3 , ou seja correspondendo a $30 \%$ do parâmetro de densidade total do universo.

Nesse caso obtém-se $t_{\text {universo }}=14$ bilhões de anos.

\section{Medidas de flutuações da radiação cósmica de fundo}

A temperatura do universo na explosão do big-bang era altíssima, acima de $10^{32} \mathrm{~K}$. Com a expansão do universo desde então, essa temperatura foi caindo, e temos hoje os restos da radiação cósmica de fundo com temperatura $\mathrm{T}=2.728 \mathrm{~K}$. Essa temperatura tem flutuações de uma direção a outra, ou anisotropias, em escalas muito pequenas, tal que só puderam ser medidas bem recentemente, em 2000, pelo experimento de medidas de balão Boomerang, e em 2002, com o satélite Wilkinson Microwave Anisotropy Probe ou WMAP.

Para se derivar todos os parâmetros cosmológicos a partir dessas medidas, foi adotado um modelo padrão de universo. Nesse modelo o universo é plano, homogêneo e isotrópico em grandes escalas. É composto por radiação, matéria (prótons, nêutrons, elétrons, neutrinos), matéria escura não bariônica constituída de partículas exóticas ainda não identificadas, e energia escura.

As galáxias e grandes estruturas vistas hoje no universo, sob forma de superaglomerados de galáxias, vazios, etc., tiveram origem com aglomeração gravitacional em torno de flutuações de energia muito pequenas, as quais foram formadas nos primeiros instantes do universo, quando este tinha em torno de $10^{-34}$ segundos de idade.

Os dados do WMAP foram combinados a dados de distribuição de galáxias em estruturas de larga escala, e foram ajustados os parâmetros do modelo que desse o melhor acordo com as observações. Resultou que a idade do universo obtida é de 13.7 \pm 0.2 bilhões de anos .

\section{A COMPOSIC̄ÃO DO UNIVERSO}

\section{Matéria bariônica}

A matéria como a conhecemos, composta de prótons, nêutrons, elétrons, os quais formam os átomos, é chamada de matéria bariônica. A quantidade máxima que possa existir desse tipo de matéria é sabida, pois pode-se comparar produções teóricas da nucleossíntese do big-bang com dados observacionais.

De fato, os elementos deutério (hidrogênio pesado), hélio e lítio foram formados durante a nucleossíntese do big-bang, e as suas quantidades puderam ser medidas, e estas têm relação direta com a densidade de bárions do universo na época (e que continua sendo a mesma até hoje). O limite é da ordem de $4 \%$ da matéria do universo.

\section{Matéria luminosa}

A estimativa da massa das estrelas e galáxias que vemos é da ordem de $1 \%$ da densidade crítica e portanto bem menor que o total da matéria bariônica! Assim sendo, a maior parte da matéria bariônica tem que estar contida em objetos não detectáveis como "Jupiters", anãs marrons (estrelas com massa menor que 0.08 massa solar), anãs brancas, estrelas de nêutrons e buracos negros, além de matéria gasosa.

\section{Matéria escura dinâmica}

A rotação das galáxias espirais pode ser medida ao longo do seu raio, por detecção da linha de hidrogênio neutro em $21 \mathrm{~cm}$. Da matéria luminosa que se vê, seria esperado que a rotação fosse decrescendo até o “fim" da galáxia, num raio da ordem de 30 kpc. Porém, mede-se que a rotação continua até raios de $50 \mathrm{kpc}$ e mais. Isso indica 
que há muito mais matéria do que se imaginava. O mesmo ocorre para galáxias anãs

Outra medida de massa dinâmica é feita em aglomerados de galáxias, onde as velocidades das galáxias, assim como do gás intra-aglomerado, indicam que as massas devem ser muito maiores que o esperado pela massa diretamente detectável.

A massa dinâmica é da ordem de $30 \%$ da matéria do universo. Como a matéria bariônica é limitada a 4\%, conclui-se que existe uma matéria escura não-bariônica. Esta é supostamente constituída por partículas exóticas, preditas nas teorias de física de partículas, embora ainda não detectadas diretamente.

\section{Energia escura}

Em 1998 um grupo europeu e um grupo americano, separadamente, chegaram à conclusão inesperada de que o universo está em expansão acelerada.

Isso foi obtido observando-se supernovas chamadas de tipo Ia, que podem ser detectadas em galáxias a grandes distâncias. A energia que impulsiona a expansão foi chamada de "energia escura". Esta parece corresponder ao que Einstein chamou de constante cosmológica, que pode ser entendida como uma força de repulsão, contrapondo-se à força da gravidade. Einstein havia colocado a constante cosmológica nas equações de modelo de universo, para tornar o universo estático (o que estava errado, como mostrou Hubble logo depois, isto é, o universo está em expansão), o que depois o próprio Einstein chamou de "o maior erro da minha vida". A boa nova é que Einstein provavelmente estava certo nisso, não sobre o universo ser estático, mas sobre existir a constante cosmológica!

Como não se sabe nada sobre a energia escura, uma classificação mais geral a denomina de "quintessência" e diferentes hipóteses vêm sendo apresentadas. Ver mais detalhes sobre a energia escura no artigo de José Ademir Sales de Lima neste dossiê.

A energia escura corresponde a aproximadamente $70 \%$ da "massa" (ou energia) do universo.

\section{CONCLUSÕES}

A astrofísica teve avanços fenomenais nos últimos cinco anos. Pela primeira vez está se chegando a um acordo sobre a idade do universo, a partir dos diferentes métodos, e essa idade é da ordem de 14 bilhões de anos

A densidade de massa do universo teve também seu valor determinado como sendo próxima da densidade crítica para fechamento (recontração) do universo. A matéria do universo é então constituída de aproximadamente $4 \%$ de matéria bariônica (matéria como a conhecemos), aproximadamente $25 \%$ de matéria escura nãobariônica, e aproximadamente $70 \%$ de energia escura.

A matéria escura não foi detectada, mas crê-se que devam ser partículas exóticas preditas pela física de partículas. Já quanto à energia escura, trata-se de física desconhecida! 